\title{
Development of a Respiration Rate Monitor for Swine
}

\author{
R. A. Eigenberg, T. Brown-Brandl, J. A. Nienaber
}

\begin{abstract}
Respiration rates were included as one measure in a study investigating bioenergetic responses of growing-finishing swine to heat challenges. Respiration rate monitors were designed around a commercially available acoustic transducer and a small battery-powered microcomputer. The monitors were designed, fabricated, and tested to provide continuous records as a basis for evaluating stress responses associated with environmental conditions. Representative data from a calorimetry study indicated the association of respiration rate and ambient temperature $(P<$ 0.01). Data reduction and analysis are also discussed, based on representative samples of collected records.
\end{abstract}

Keywords. Bioenergetic, Microcomputer, Respiration rate monitor, Swine, Transducer.

$\mathrm{R}$

espiratory heat transfer is an important method of heat loss for most mammals (homeotherms) over a broad range of environmental conditions (Ingram and Mount, 1975). Respiration rate (RR) provides a visually observable measure of an animal's response to thermal conditions. Respiration rate can be an important physiological parameter when used with other information, such as ambient temperature $\left(\mathrm{T}_{\mathrm{a}}\right)$, humidity, radiation heat loads (Garrett et al., 1967; Hahn, 1976), and air velocity (Monteith, 1974). Intensive studies of swine subjected to various thermal conditions have shown RR to respond predictably, increasing as $\mathrm{T}_{\mathrm{a}}$ rises (Brown-Brandl et al., 1998; Liao and Veum, 1994). However, respiration rate response is non-linear. As $\mathrm{T}_{\mathrm{a}}$ increases beyond a threshold, RR increases exponentially (Brown-Brandl et al., 1998). An improved understanding of the RR signature for swine would provide researchers a better interpretation of physiological response to thermal conditions, as well as provide a better tool for producers to recognize animal distress and to initiate planned intervention to minimize performance or death losses.

Respiration rate can be measured by traditional means (e.g., observing flank movement and using a stopwatch), but long-term studies that require frequent periodic measures become tedious and labor intensive. Additionally, intrusions to observe the animals may influence the measurements. Automated RR monitoring can help alleviate some of these

Article was submitted for review in October 2001; approved for publication by the Structures \& Environment Division of ASAE in June 2002.

Names are necessary to report factually on available data; however, the USDA neither guarantees nor warrants the standard of the product, and the use of the name by USDA implies no approval of the product to the exclusion of others that may also be suitable.

The authors are R. A. Eigenberg, ASAE Member Engineer, Agricultural Engineer, T. Brown-Brandl, ASAE Member Engineer, Agricultural Engineer, and J. A. Nienaber, ASAE Member Engineer, Agricultural Engineer, USDA-ARS U.S. Meat Animal Research Center, Clay Center, Nebraska. Corresponding author: R. A. Eigenberg, USDA-ARS U.S. Meat Animal Research Center, P.O. Box 166, Clay Center, NE 68933; phone: 402-762-4272; fax: 402-762-4273; e-mail: eigenberg@email.marc.usda.gov. concerns, as well as provide more consistent data and an increased frequency of response dynamics measurement.

Existing automated RR equipment is quite limited, and unsuitable for swine. A respiratory effort transducer (BIOPAC Systems, 1997) incorporates a thin-film transducer into a silicone rubber strain assembly that changes resistance with changing thoracic or abdominal circumference and has been used primarily for human applications. That transducer has been successful for cattle (Eigenberg et al., 2000); however, tests have shown it to be unsuitable for swine as they spend much of their time resting, and their body shape has less definitive respiratory movement than cattle. Another problem is that few devices are available for free-ranging animals. Data Sciences International has developed a method that provides accurate determination of respiratory rate for free-moving rats monitored via implanted telemetry sensors (Data Sciences International, 1996). The technique is patent-pending and is based on changes in cardiovascular data resulting from respiratory effort. The application to larger animals is still not fully developed.

The purpose of this work is to develop respiration monitors suitable for use on swine. These units are intended to measure and store respiration rates under various laboratory and field conditions. These units will be tested under laboratory conditions to determine functionality and reliability.

\section{Materials ANd Methods}

A respiration monitoring system was designed with three major components: (1) a respiration rate sensor with signal amplifier and conditioner, (2) a data logging device capable of recording the respiration data and transferring it as data files for analysis, and (3) the analysis program that allows the data to be interpreted. Each of the components is described in the sections that follow.

\section{RESPIRATION RATE SENSOR AND Electronics}

A critical component of a respiration rate monitor is the respiration rate sensor. Traditional methods of measuring abdominal circumference changes with respiration are difficult to implement with swine. Tests with a stethoscope 


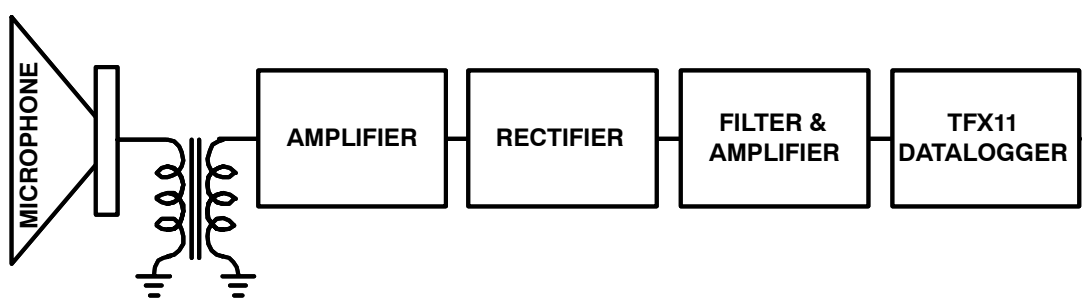

Figure 1. Block diagram of respiration monitor for pigs.

determined that there is an audible component of pig respiration that had the potential of being detected and recorded. Based on results of initial tests, a respiration rate monitor for swine was developed that utilized auditory response.

The RR sensor used in this application is a small speaker (Radio Shack, RS 273-092 or equivalent) with a plastic diaphragm. The speaker acts as an audio pickup device and is placed in external contact with the pig's throat, where it responds to air movement through the larynx, much like a stethoscope. The sensor is held in place using a bandaging tape. The audio signal is coupled through a matching transformer to the signal conditioner circuits (fig. 1).

Signal conditioning is used to provide a meaningful signal to the data logger that represents the respiration rate of the animal. The audio signal from the audio sensor goes through several stages of amplification, which include AC coupling to eliminate any DC bias. The signal is then rectified using an ideal diode circuit built around an operational amplifier (fig. 1). The filtered signal is then amplified to a level matching the input range of the data logger used for the respiration monitor.

\section{DAta Logger}

A micro-power small-board computer (TFX-11; Onset Computer, 1997) was used as the data collection device (fig. 2). The TFX-11 specifications include small size $(8.1 \mathrm{~cm} \times 5.33 \mathrm{~cm} \times 1.27 \mathrm{~cm}), 12-$ bit A/D converter, built-in real-time clock, $512 \mathrm{~K}$ of EEPROM, and an ultralow power mode. These specifications met the requirements for the respiration monitor data-capture device. The TFX-11 is equipped with 0.1 -inch headers for electrical connection to an interface board. A user-developed interface board was designed based on a prototype unit using a CAD printed circuit board design program. All communication and analog signals connect to the TFX-11 through the interface board, with all signal conditioning and logger power switching handled on the interface board. The complete respiration data logging system is shown in figure 3 . The entire respiration rate logging system cost approximately $\$ 400$ for the components.

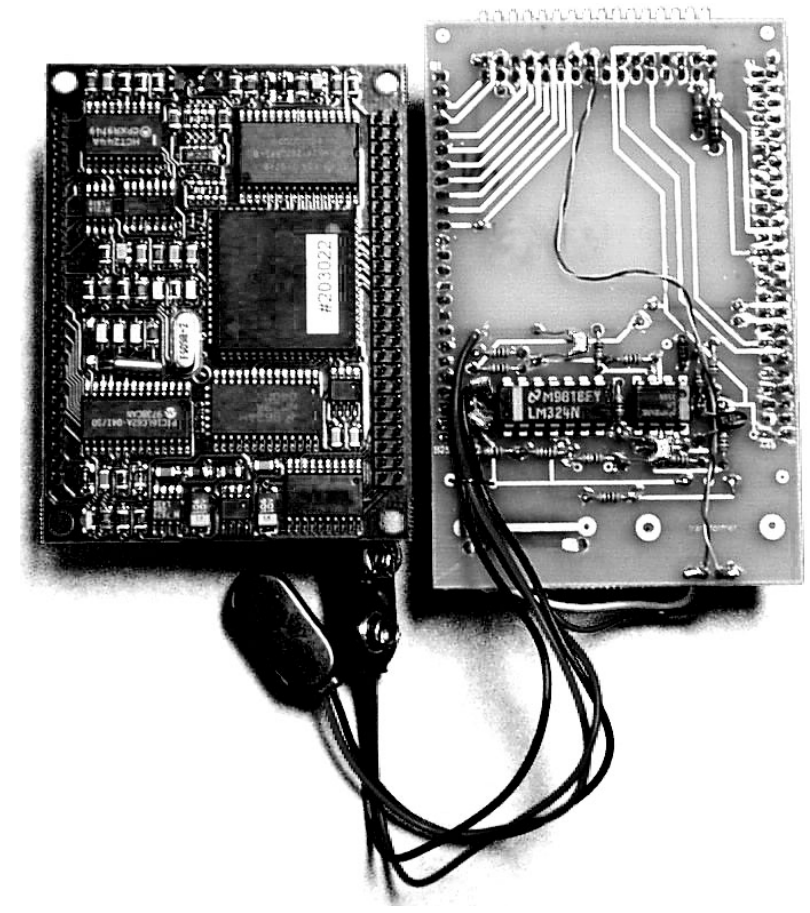

Figure 2. A micro-power small-board computer is used as the data collection device. The interface board provides signal conditioning and power control for the data logging application.

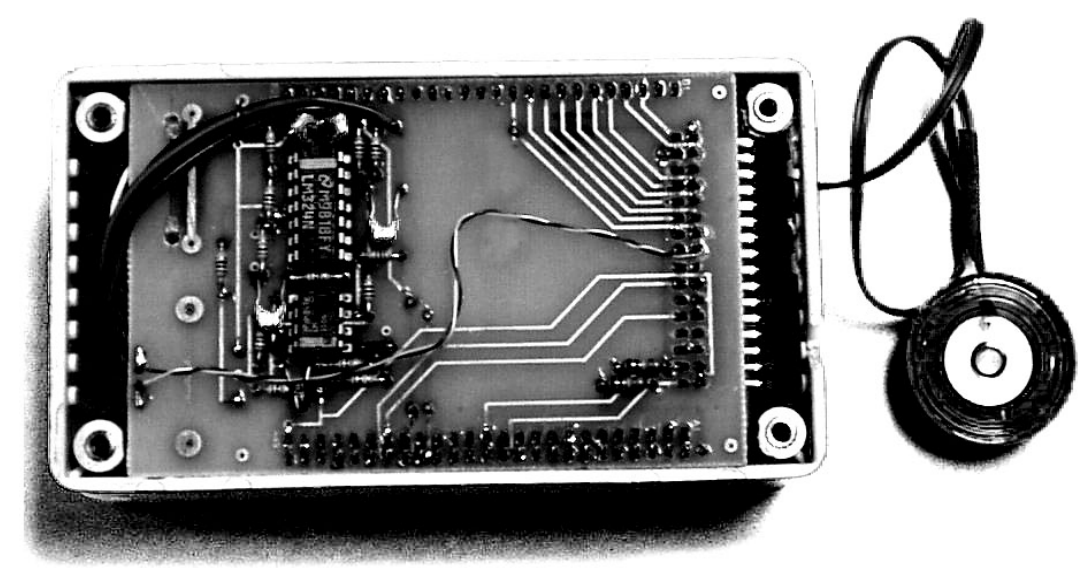

Figure 3. Complete respiration data logging system. 


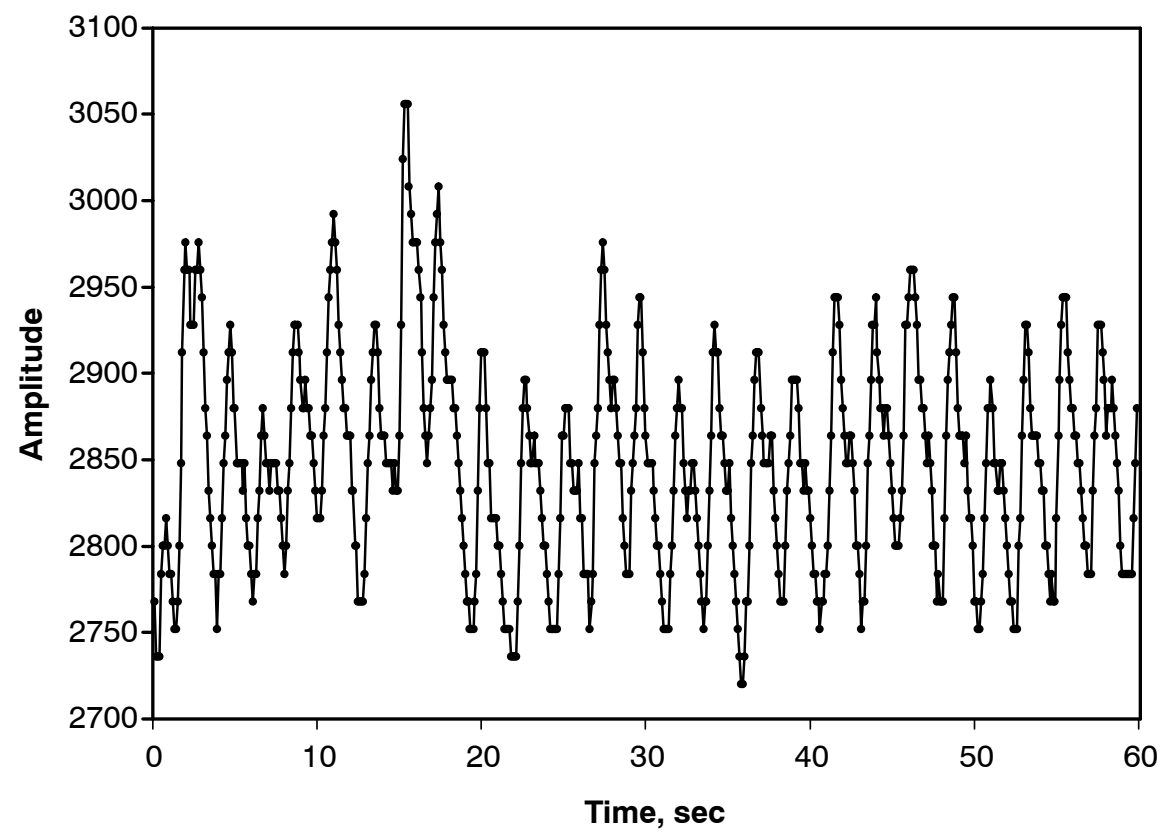

Figure 4. Sample of respiration data collected during a one-minute burst. Sample frequency was 10 records/second.

\section{RESPIRATION MONITOR SUPPORT SOFTWARE}

Programming the TFX-11 is accomplished via a development program from Onset Computer Corporation. The instruction set for the TFX-11 is a modified BASIC programming language. Onset Computer provides specialized commands that perform routine tasks such as data acquisition and time functions. The data logger program was written to support RR signal logging bursts of user-defined periods. During the logging bursts, respiration sensor outputs were recorded every 0.1 second. Data are stored in binary format in the on-board EEPROM and offloaded as binary data. The TFX-11 EEPROM memory is sufficient for collection of respiration data over a 4-day collection span, with one-minute bursts acquired every 15 minutes. Figure 4 shows sample respiration data output for a one-minute burst for a pig (ID No. 905). The sample burst demonstrates the hardware and software capabilities and the challenges of record interpretation. Many of the peaks in the record show a compound or spurious peak. This type of pattern was observed in many of the records collected from the experimental tests. Further evaluation is planned to determine if the peaks are breathing artifacts or a result of other physiological noise, such as blood flow through an artery.

A second program converts the data from binary format to ASCII. The data is processed by a Visual Basic program that transforms the ASCII respiration data into graphical format for analysis. The program calculates the respiration rate based on the entire record for each one-minute interval. The operator has the option of accepting the one-minute record as is, selecting a more representative portion of the data set, or eliminating the record. Each one-minute sequence is examined, and a RR is computed from the record; the time and RR are then stored in an output file. A program was written to automate the data reduction process. Human interpretation and the automated system were compared for all treatments and pigs. The automated system and human operator yielded RR values that were on average within $\pm 10 \mathrm{bpm}$. Files could deviate greatly if there was error in the
RR system, such as a shift in the sensor placement. The value of having full files to be reviewed by a human operator, rather than on-board data reduction, is apparent in these cases.

\section{Calorimeter Study: Results AND Discussion}

The results and discussion of the studies are presented to demonstrate the efficacy of the USMARC swine RR monitors to measure this important physiological parameter. This section is neither a summary of all of the experimental results nor does it explore all of the ramifications of the physiology involved. A detailed summary of results is contained in Brown-Brandl et al. (2000). Accuracy of swine RR measurements was tested by comparing RR based on counts of flank movements timed by a stopwatch with the RR measurements of the respiration monitor at the same logging periods. For this test, the manual counts resulted in a RR of $46.5 \pm 12.6 \mathrm{bpm}$, and the respiration monitor with computeraided data reduction indicated $45.7 \pm 7.2 \mathrm{bpm}(\mathrm{N}=24)$.

The laboratory study of the respiration monitors, conducted in the USMARC calorimeters, focused on the effects of acute exposure to various warm or hot temperatures on activity, heat production, respiration rate, and core body temperature. The protocol imposed temperatures of $18^{\circ} \mathrm{C}$, $24^{\circ} \mathrm{C}, 28^{\circ} \mathrm{C}$, and $32^{\circ} \mathrm{C}$ for a $22 \mathrm{~h}$ acute exposure in a Latin-Square design. Figure 5 is a segment of the experiment showing chamber temperature and respiration data for one pig (ID No. 905) during the exposure to all four temperature treatments. A straight-line fit (fig. 6) of RR data versus ambient temperature showed an approximate $3.8 \mathrm{bpm}$ change for a $1.0^{\circ} \mathrm{C}$ change of $\mathrm{T}_{\mathrm{a}}$ for this animal under these conditions. The correlation (Pearson correlation coefficient; SAS, 1985) of respiration rate to temperature change was found to be $0.47(\mathrm{P}<0.01)$. The respiration monitors were used for an 8-week period in this experiment. 


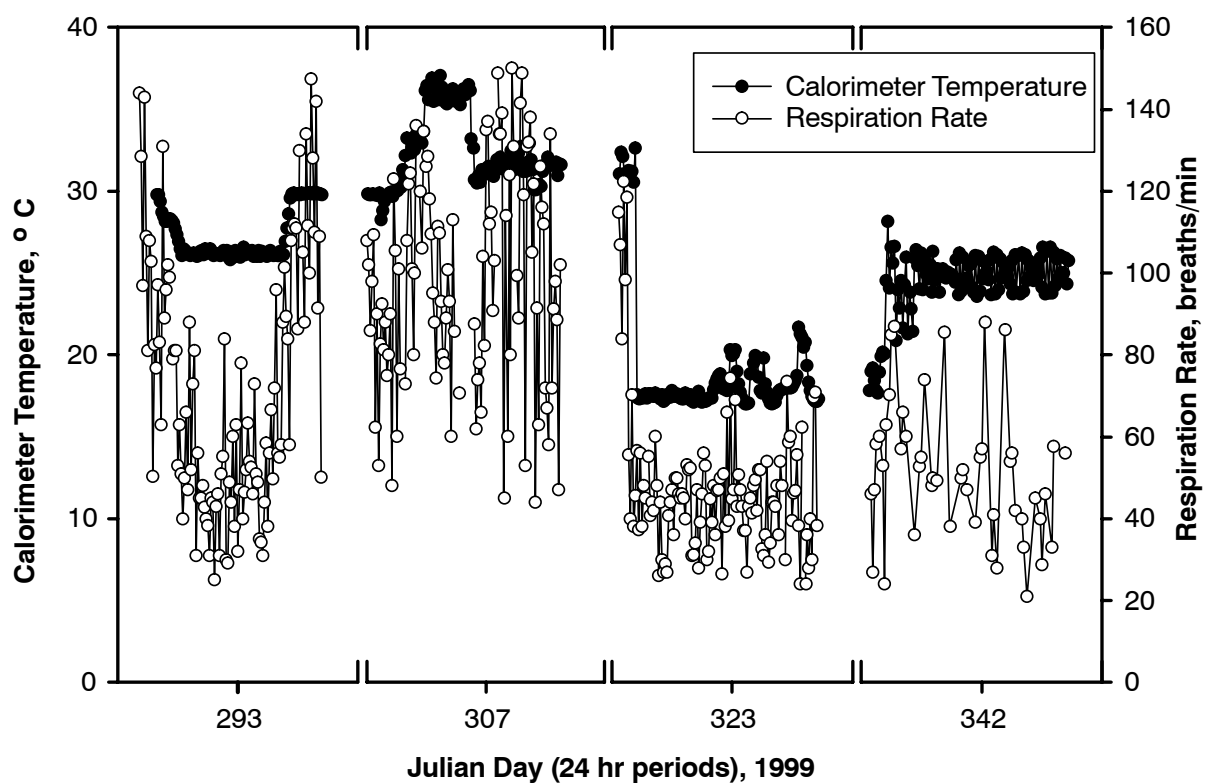

Figure 5. Data showing the response of one pig (ID No. 905) during exposure to four temperature treatments.

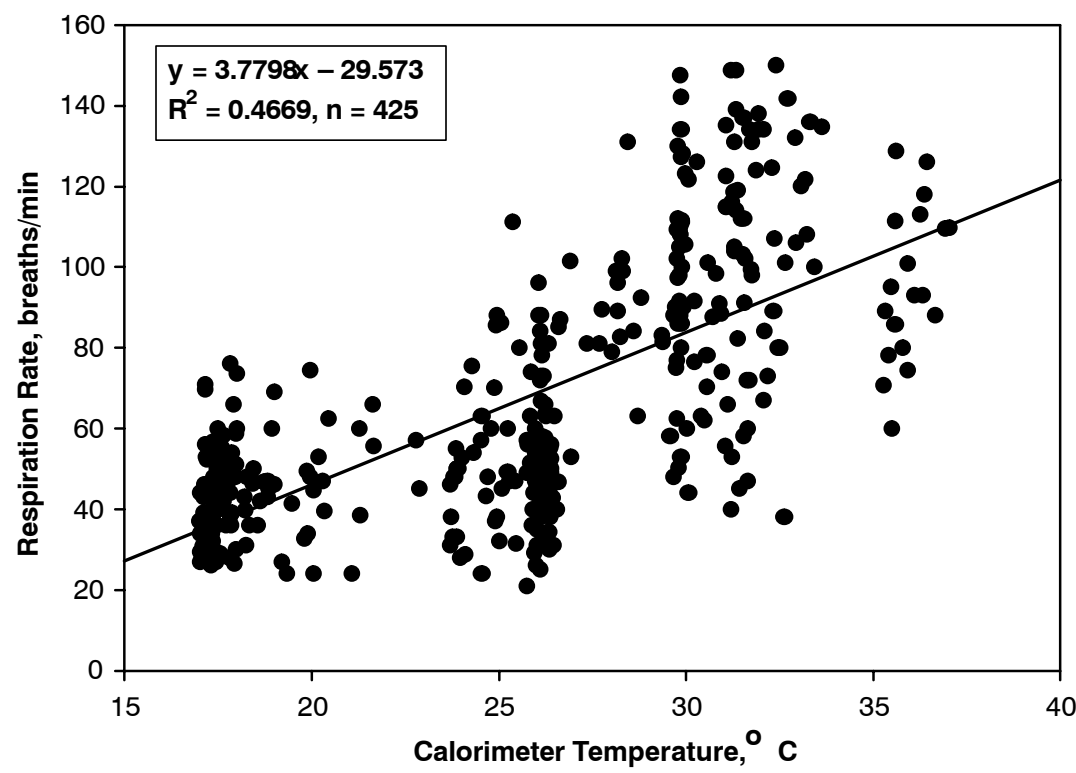

Figure 6. Respiration rate versus calorimeter temperature. Straight line fit to data shows an approximate 3.8 respirations per minute change for a $1.0^{\circ} \mathrm{C}$ temperature change for this pig in this range of temperatures.

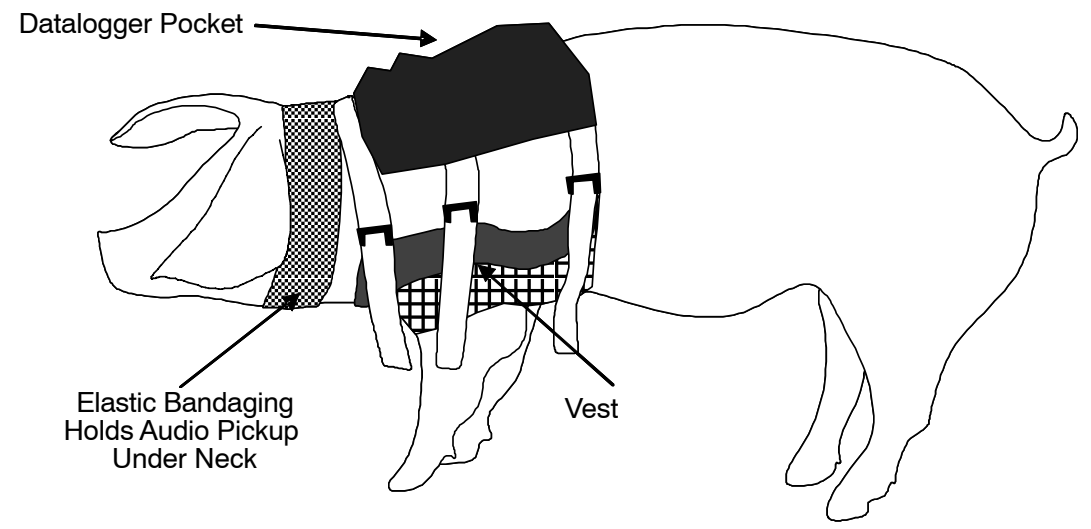

Figure 7. Sensor is placed under the pig's throat, held in place initially with an adhesive tape, and then wrapped with an elastic wrap. 
The tests of the hardware were successful, with the equipment successfully recording breathing activity. Mounting of the sensor is critical, and techniques were developed to keep the sensor in place through the trial period. Figure 7 illustrates the sensor placement and mounting method. The sensor is initially held in place with an adhesive tape and then wrapped with an elastic wrap. Sensors proved to be durable, typically lasting for the length of the experiment. The automated data reduction software is being evaluated with alternative methods to determine RR, such as Fourier analysis, which shows promise for improved accuracy.

\section{SUMMARY}

Rugged respiration monitors for swine were designed and tested. A calorimeter study demonstrated the value of the automated measurement in evaluating the physiological condition of the animals. Representative data from this study indicated the association of $\mathrm{RR}$ and $\mathrm{T}_{\mathrm{a}}\left(\mathrm{R}^{2}=0.47, \mathrm{P}<0.01\right)$, with step changes being evident during exposure to the various levels of constant ambient temperatures. The respiration monitoring system performed well, and with the experience gained from initial tests, an improved version should prove very useful during future experiments in laboratory and production settings.

\section{ACKNOWLedgements}

The authors would like to acknowledge John Holman and Diane Purcell for their contributions to this project.

\section{REFERENCES}

BIOPAC Systems. 1997. MP100 Catalog. Santa Barbara, Cal.: BIOPAC Systems, Inc.

Brown-Brandl, T. M., J. A. Nienaber, and L. W. Turner. 1998. Acute heat stress effects on heat production and respiration rate in swine. Trans. ASAE 41(3): 789-793.
Brown-Brandl, T. M., R. A. Eigenberg, J. A. Nienaber, and S. A. Kachman. 2000. Acute heat stress effects on heat production, respiration rate, and core body temperature in growing-finishing swine. ASAE Paper No. 004070. St. Joseph, Mich.: ASAE.

Data Sciences International. 1996. Telemetry Times. Volume 10, No. 3.

Eigenberg, R. A., G. L. Hahn, J. A. Nienaber, T. M. Brown-Brandl, and D. E. Spiers. 2000. Development of a new respiration rate monitor for cattle. Trans. ASAE 43(3): 723-728.

Garrett, W. N., T. E. Bond, and N. Pereira. 1967. Influence of shade height on physiological responses of cattle during hot weather. Trans. ASAE 10(4): 433-434, 438.

Hahn, G. L. 1976. Shelter engineering for cattle and other domestic animals. In Progress in Animal Biometeorology 1: 496-503. H. D. Johnson, ed. Amsterdam, The Netherlands: Swets and Zeitlinger.

Ingram, D. L., and L. E. Mount. 1975. Heat exchange between animal and environment. Chapter 2 in Man and Animals in Hot Environments, 5-23. K. E. Schaefer, ed. New York, N.Y.: Springer-Verlag.

Liao, C. W., and T. L. Veum. 1994. Effects of dietary energy intake by gilts and heat stress from days 3 to 24 or 30 days after mating on embryo survival and nitrogen and energy balance. J. Anim. Sci. 72(9): 2369-2377.

Monteith, J. L. 1974. Specification of the environment for thermal physiology. Chapter 1 in Heat Loss from Animals and Man, 1-17. J. L. Monteith and L. E. Mount, eds. London, U.K.: Butterworth.

Onset Computer. 1997. TFX-11 Remote Datalogger/Controller Engine Users's Guide. Bourne, Mass.: Onset Computer Corp. SAS. 1985. SAS User's Guide. Cary, N.C.: SAS Institute, Inc.

\section{Abbreviations}

$\begin{array}{ll}\mathrm{bpm} & =\text { breaths per minute } \\ \mathrm{RH} & =\text { relative humidity } \\ \mathrm{RR} & =\text { respiration rate } \\ \mathrm{T}_{\mathrm{a}} & =\text { ambient temperature } \\ \mathrm{USMARC} & =\text { U.S. Meat Animal Research Center }\end{array}$


